\title{
Study on Awareness Regarding Consumption of Functional Foods With Reference To Cancer Prevention
}

\author{
Purnima shah ${ }^{1}$, Shailja jain ${ }^{2}$ \\ ${ }^{1-2}$ Department of Home science (Food and Nutrition) Govt. K. R. G. Autonomous College, Gwalior 474011, \\ (Madhya Pradesh), INDIA
}

\begin{abstract}
Cancer is the leading cause of death among adults. The scientific consensus is that cancers are largely preventable, and one of the most effective means of reducing risk is consumption of appropriate diets. Great efforts have been made in the last few years to identify active components in the diet reducing cancer risk, to understand the mechanism of cancer prevention, to give better dietary recommendation to reduce cancer risk and cancer incidences. To assess knowledge about people's understanding, the present study has been conducted on 100 cancer patients (aged 25 years and above), selected from different clinics and Cancer Hospital of Gwalior. The interview schedule was prepared for assessment of knowledge level, attitude towards functional food and consumption practice of selected 10 functional food items, which are rich in antioxidants, phytochemicals and other important substances. They have cancer preventive and curing power. Knowledge gathered from the patients was scored as per Lickert's scale. Results showed that no patients had high level of knowledge whereas most (95\%) had low level of knowledge. Though the attitude of the subjects towards functional food was positive in 50\% cases, but the consumption level of functional food was either average $(16 \%)$ or low (84\%). With reference to rural and urban community no significant difference was found in their knowledge and attitude level. Similarly no significant difference was found in the male and female attributes. However, a significant positive correlation at 0.01 levels was found between knowledge and practice of consumption of functional food. Similar trend was also observed between attitude and practice of consumption of functional food. A very strong correlation between knowledge and attitude was found at 0.01level of significance. The results obtained show that there is an urgent need to spread awareness of functional food and its benefits among people through health education programmes.
\end{abstract}

Keywords: Functional Foods, Antioxidants, Cancer, Awareness.

\section{INTRODUCTION}

Cancer is now a major cause of mortality throughout the word. Approximately $90 \%$ of all cancer cases correlate with environmental factors, including one's dietary habits (Armstrong and Doll, 1975, Doll, 1992, Potter, 1992). Lifestyle is a term to describe the way a person lives. The specific causes of cancer are still not fully understood. Scientist agree that most cancers are linked to (lifestyle) how you live and where. To what you eat, drink, breath and smoke. A healthy lifestyle and diet is more appropriate for winning the war against cancer. Lifestyle modification can effectively control risk factors of cancer and lower the incidence.

Although great advances have been made in prevention and treatment of cancer through drug therapies and procedure, diet and lifestyle therapies remain the foundation of clinical intervention for prevention.

Functional foods can be defined as those providing health benefits beyond basic nutrition and include whole, fortified, enriched or enhanced foods which have a potentially beneficial effect on health when consumed as part of a varied diet on a regular basis at effective levels (Clare M, Hasler, 2000).

Several dietary constituents modulate the process of carcinogenesis and prevent genotoxicity. . Foods may inhibit cancer by changing the bioactivation / detoxification of foreign compounds, altering growth regulators such as intracellular cAMP (cyclic AMP) concentrations and/or serving as anti hormones.

\section{Potential Anti carcinogenic Indian Foods and possible mechanisms of action.}

1. Vitamin C:

Vitamin C modifies tumor proliferation, inhibits the action of cytotoxic drugs and interferes with tumor cell metabolism.

2. Vitamin A:

Carotenoids, retinol and retinoic acid interact with specific intracellular receptors and affect protein synthesis finally controlling cell chromatin, cell growth and cell differentiation(Lokshin A, 1999).

3. Selenium:

Selenium is a naturally occurring (Jwar and Bajra) ant carcinogenic trace element. The ability of various forms of selenium to inhibit experimentally induced tumors is well documented (Liu, 1991). 
4 Vitamin E:

It is an important natural anti-oxidant and scavenger. Vitamin E produces 30-60 percent inhibition of induced carcinogenesis due to its ability to inhibit synthesis of nitrosamine compounds.

5. Allium Plants:

An allium plant, like Gariic, Onian, and Leeks has anti-cancer properties (Block, 1992). Interestingly, garlic not only inhibits bacteria and fungi-mediated synthesis of nitrite and nitrosamines, but also directly inhibits the spontaneous synthesis of nitrosamines. Diallyl sulfide, a flavor component of garlic, completely inhibited N-nitrosomethy / benzylamine-induced esophageal tumors(Wagovich et al., 1988, 1990) .Some garlic compounds modify enzymatic activities involved in carcinogen activation and deactivation.

6. Soybean:

Soybean contains protease inhibitor and phytic acid, high levels of the isoflavones genistein and daidzein, and their glucosides, and may lower the risk of CVD, osteoporosis and cancer. Dietary rye bran and Soy Phytoestrogens decrease testosterone levels and prostate weight without altering leutinising hormone (LH) (Ansari, 2002).

7.Cruciferous vegetables

High intake of cruciferous vegetables is associated with low cancer risk (Kune 1992). A variety of indole derivatives and isothiocyanates occur naturally in cruciferous vegetables.

8. Flax seeds:

Flax contains essential fatty acids which influence cellular proliferation, tissue invasiveness, metastatic spread of tumors and immune response. Diets high in W-3 fatty acids (EPA and DHA) have beneficial effects against several types of malignant tumors (Cave, 1991; Diaz, 2000). Because EPA and DHA inhibit both the cyclo-oxygenase and lipoxygenase pathways, it is suggested that the ecosanoids produced by EPA and DHA modulate the induction and proliferation of tumor cells by altering immune function and oncogene expression, and possibly exerting a direct action on growth factor. It is a rich source of lignan- a well documented anticancer agent.

\section{Dietary Fibers:}

The possible action of fiber may be to reduce transit time in the bowel, thereby reducing the time the bowel is in contact with potential carcinogens, altering the intestinal microflora; binding potentially carcinogenic agents; diluting toxic compounds by virtue of its hydro-philic property; and/or changing the biological behaviour of intestinal cells, including their response to gut hormones.

\section{OBJECTIVE}

To assess the knowledge, attitude, and practice of consumption of functional foods in patients suffering from cancer for study on awareness regarding functional foods.

\section{MATERIAL AND METHOD}

The sample of 100 subjects has been chosen from cancer hospital and clinics of Gwalior city by purposive sampling. An interview schedule was prepared for assessment of nutritional status, lifestyle, knowledge, attitude and practice of consumption of selected 10 Functional food items, which are rich in antioxidants, phytochemicals, and other important substances. A likert type summated scale was developed to assess attitude of the patients. Knowledge gathered from patients was scored and statistical treatment (correlation and t-test) has been applied.

\section{OBSERVATION}

Table 1 Distribution of patients according to knowledge, attitude, and practice of consumption level of functional foods.

\begin{tabular}{|c|l|c|c|c|}
\hline $\begin{array}{c}\text { S. } \\
\text { No. }\end{array}$ & Level of scores & $\begin{array}{l}\text { Knowledge } \\
\text { level }\end{array}$ & $\begin{array}{l}\text { Consumption } \\
\text { level }\end{array}$ & Attitude \\
\hline 1 & High & Nil & Nil & $\begin{array}{c}\text { Positive } \\
50 \%\end{array}$ \\
\hline 2 & Average & $5 \%$ & $16 \%$ & $\begin{array}{c}\text { Neutral } \\
37 \%\end{array}$ \\
\hline 3 & Low & $95 \%$ & $84 \%$ & $\begin{array}{c}\text { Negative } \\
13 \%\end{array}$ \\
\hline
\end{tabular}


Table 2 Correlation of attitude and consumption of functional foods in relation to knowledge level.

\begin{tabular}{|c|c|c|c|}
\hline $\begin{array}{c}\text { S. } \\
\text { No. }\end{array}$ & $\begin{array}{l}\text { Knowledge level } \\
\text { regarding f.f. }\end{array}$ & Consumption level & Attitude of patients \\
\hline 1 & High & $\begin{array}{ll}\text { High } & - \\
\text { Average } & - \\
\text { Low } & \end{array}$ & $\begin{array}{ll}\text { Positive } & - \\
\text { Neutral } & - \\
\text { Negative }\end{array}$ \\
\hline & Total $=$ & Nil & Nil \\
\hline 2 & Average & $\begin{array}{lc}\text { High- } & \text { Nil } \\
\text { Average } & 03 \\
\text { Low } & 02\end{array}$ & $\begin{array}{lc}\text { Positive } & 04 \\
\text { Neutral } & 01 \\
\text { Negative } & \text { Nil }\end{array}$ \\
\hline & Total $=$ & 05 & 05 \\
\hline \multirow[t]{3}{*}{3} & Low & $\begin{array}{lc}\text { High } & \text { Nil } \\
\text { Average } & 13 \\
\text { Low } & 82\end{array}$ & $\begin{array}{lc}\text { Positive } & 46 \\
\text { Neutral } & 36 \\
\text { Negative } & 13\end{array}$ \\
\hline & Total $=$ & 95 & 95 \\
\hline & Correlation $=\mathrm{r}$ & $\begin{array}{l}.348^{* *} \\
\text { (significant) }\end{array}$ & $\begin{array}{l}.638^{* *} \\
\text { (Significant) }\end{array}$ \\
\hline
\end{tabular}

Table 3 Test of significance (t- test) for knowledge, attitude, and practice of functional foods consumption between subjects.

\begin{tabular}{|l|l|l|l|}
\hline Source of variation & $\begin{array}{l}\text { t- value } \\
\text { urban/rural }\end{array}$ & $\begin{array}{l}\text { t-value } \\
\text { male/female }\end{array}$ & Remark \\
\hline Knowledge DF-98 & -3.655 & -.474 & N.S. \\
\hline Attitude DF-98 & -2.518 & -.345 & N.S. \\
\hline Consumption DF-98 & -1.833 & .300 & N.S. \\
\hline
\end{tabular}

\section{RESULT}

In present study most of the cancer patients were consuming inappropriate diet. Almost all nutrients were found far below than the recommendations of ICMR.

$95 \%$ patients had low level of knowledge regarding functional foods. only $16 \%$ of patients having average consumption level .Rest of the patients having very poor practice of consumption of functional foods. $50 \%$ patients having positive attitude towards functional foods.

There is no significant difference was found in knowledge, attitude and practice of consumption of functional foods at 0.05 level of significance between male/female subjects and urban/rural subjects.

A significant positive correlation was found at 0.01 level of significance, between knowledge level and attitude of patient regarding functional foods, as well as knowledge level and practice of consumption of functional foods.

\section{CONCLUSION}

Thus study indicated that there is a lack of knowledge of modifiable risk factors for cancer, as well as preventive and therapeutic properties of functional foods among the subjects, they also have very poor practices of consumption of functional foods, and an urgent need to spread awareness and education intervention programme for possible prevention of cancer.

\section{SUGGESTIONS}

Some preventive interventions early in the life course offer lifelong benefits to the people.

- Knowledge regarding risk factors should be provided.

- Nutritional awareness can play a vital role in prevention of cancer, hence the knowledge regarding healthy diet and functional foods should be introduced at school level.

- A minimum daily intake of $30 \mathrm{gm}$ of fiber is recommended through regular consumption of whole grain cereals, legumes, fruits and vegetables.

- Physical activity should be increased to achieve and maintain healthy body weight. Tobacco chewing, smoking and excess consumption of alcohol should be avoided.

- Minimize intake of refined carbohydrate, foods with trans fats, refined oil, junk foods, preserved foods, energy dense cold drink and beverages.

- An emphasis on balanced/prudent diet is also appropriate to ensure nutrient adequacy and energy balance. 
- Consumption of a variety of vegetables and fruits has been recommended, vegetable and fruits that are deeply colored throughout (e.g. spinach, carrots, peaches, berries) should be emphasized because they tend to be higher in micronutrient than other vegetable and fruits such as potatoes and corn. Fruits and vegetables at least $400 \mathrm{gm} . / \mathrm{day}$

Antioxidant supplements are not recommended, plant derived food sources rich in antioxidants, have been recommended. Taken together antioxidants are helpful, but are not a magic bullet against cancer. Along with exercise, a positive attitude and an overall healthful, whole food diet, antioxidants are invaluable tools to prevent cancer and prolong a healthy life.

\section{References}

[1] Ansari, M.S. Prostate Cancer and Nutritional issues. The Ind. J. Nutr. Dietet (2002), 29, 237

[2] Block et al. Fruit, vegetables, and cancer prevention A review of the epidemiological evidence. Nutr. Cancer 1992,18:1-29.

[3] Cave W.T. W-3 F.A. effects on tumorigenesis in experiemental animals. In Health Effects of W-3 Polyunsaturated F.A. Sea Foods ,Vol. 66, 1991,A.P. Simopoulos, R.R. Kifer, R.E. Martin, and S.M. Barlow, eds, pp. 74-86. Basel Karger.

[4] Clave M. Hasler. The changing Face of Functional Foods . Jr. of the American College of Nutrition.2000, Vol. 19, No. 90005, 49955068

[5] Doll, R. The lessons of life: Keynote address to the nutrition and cancer conference. Cancer Res.1992, 52:2024s-2029s.

[6] Kune et al. Diet, alcohol, smoking, serum beta carotene, in male nonmelanocytic skin cancer patients and control. Nutr. Cancer ,1992 ,18:237-244.

[7] Liu et al. Inhibition of 7, 12-dimethyl benz(a)anthracene induced mammary tumors and DNA adducts by dietary selenite. Cancer Res. 1991, 51: 4613-4617.

[8] Lokshin A, Zhang H, Mayotte J. et al. Early effects of retinoic acid on proliferation, differentiation and apoptosis in non-small cell lung cancer lines. Cancer Res. 1999 Nov-Dec. 19(68):5251-

[9] Potter, J.D. Epidemiology of diet and cancer : Evidence of human maladaptation in Macronutrients. Investigating their Role in cancer. M.S. Micozzi and T.E. Moon eds. pp. 55-84. New York : Marcel Dekker ,1992.

[10] Wargovich et al. Chemo prevention studies in animal models for colon and esophageal cancer using diallyl sulfide. In Garlic in Biology and Medicine: I st World Congress on the Health significance of Garlic. Nutr. Int. Con. 1988\&1990, P.O. Box 50632, Irvine CA92619-0632. 